\title{
SUPLEMENTAÇÃO ENERGÉTICA ASSOCIADA OU NÃO À URÉIA E/OU MONENSINA SÓDICA PARA NOVILHAS DE CORTE
}

\author{
Paulo Santana PachecoO ${ }^{1}$, Jỗo Restle ${ }^{2}$, Fernando Kuss ${ }^{3}$, Luis Fernando GlasenapP \\ MENEZES $^{3}$, JOILMARO PEREIRA ROSA ${ }^{1}$, IVAN LUIZ BRONDANI ${ }^{1}$ \\ ${ }^{1}$ Professores Doutores da Universidade Federal de Santa Maria, Santa Maria, RS. \\ ${ }^{2}$ Professor Doutor Visitante, Universidade Federal do Tocantins, Araguaína, TO. \\ ${ }^{3}$ Professores Doutores da Universidade Tecnológica Federal do Paraná, Dois Vizinhos, PR - $\underline{\text { fgdmdm@yahoo.com.br }}$
}

Avaliou-se o efeito da suplementação energética, na forma de grão de aveia moído puro (AV), associado com uréia (AVU), com monensina sódica (AVM) ou com uréia mais monensina (AVUM), no desempenho de 116 novilhas Charolês (C), Nelore (N) e mestiças com predominância de $\mathrm{C}(\mathrm{CN})$ ou $\mathrm{N}(\mathrm{NC})$, durante o final do verão $(\mathrm{FV})$ e o início do outono (IO). As novilhas com idade de 15 meses e peso médio inicial de $243,1 \mathrm{~kg}$ foram mantidas em pastagem nativa. $\mathrm{O}$ suplemento foi fornecido em quantidade equivalente a $0,7 \%$ do peso vivo. O ganho de peso médio diário (GMD) foi superior para as novilhas recebendo o suplemento combinando AVUM (539 g) em relação à $\mathrm{AV}(430 \mathrm{~g})$ e AVU (380 g), porém foi similar estatisticamente à combinação de AVM (488 g).

PALAVRAS-CHAVE: aveia; Charolês; ionóforo; Nelore.
Observou-se que os tratamentos que incluíram monensina proporcionaram melhor conversão (3,58 e 3,46, para aveia + monensina e aveia + monensina + uréia) em transformar o suplemento em ganho de peso. No FV o GMD foi maior que no IO (525 vs $394 \mathrm{~g}$ ). Para as novilhas $\mathrm{C}, \mathrm{CN}, \mathrm{N}$ e $\mathrm{NC}$, o GMD no FV foi de 370, 517, 560 e $691 \mathrm{~g}$ e no IO foi 427, 398, 317 e $397 \mathrm{~g}$, respectivamente. Novilhas $\mathrm{N}$ apresentaram menor peso vivo em relação aos demais grupos genéticos. $\mathrm{O}$ escore da condição corporal no FV e IO foi melhor para as novilhas $\mathrm{CN}$ que não diferiu das $\mathrm{NC}$, com as $\mathrm{C}$ apresentando escore intermediário e as $\mathrm{N} \mathrm{o}$ pior escore. A associação da monensina com uréia favorece o ganho de peso dos animais mantidos em campo nativo e suplementados com grão de aveia.

\section{ENERGETIC SUPPLEMENTATION ASSOCIATED OR NOT WITH UREA AND/OR MONENSIN FOR BEEF HEIFERS}

\section{ABSTRACT}

The effect of energetic supplementation, in the form of grounded oat grain (OT), associated with urea (OTU), with monensin (OTM), or with urea plus monensin (OTUM), on the performance of 116 Charolais (C), Nellore $(\mathrm{N})$ and crossbreds with predominance of $\mathrm{C}(\mathrm{CN})$ or $\mathrm{N}$ (NC) heifers was evaluated during the end of summer (ES) and beginning of autumn (BA). The 15month-old heifers, with initial weight of $243.1 \mathrm{~kg}$, were kept on native pasture and supplemented with an amount of .7\% of live weight. The average daily weight gain (ADG) was higher for heifers supplemented with the combination OTUM $(538 \mathrm{~g})$ in relation to OT $(430 \mathrm{~g})$ and OUT (380 g), however it was statistically similar to the combination OTM (488 g). Treatments that included monensin showed higher efficiency of converting the supplement into weight gain. During ES, the ADG was higher than during the BA (525 vs $394 \mathrm{~g}$ ). For C, CN, N and $\mathrm{NC}$ heifers, the ADG during ES was 370, 517, 560 and $691 \mathrm{~g}$ and during BA it was 427, 398, 317 and $397 \mathrm{~g}$, respectively. Nellore heifers showed lower live weight than the other genetic groups. Body condition score at the end of ES and BA was higher for $\mathrm{CN}$ heifers which did not differ from $\mathrm{NC}$, with $\mathrm{C}$ showing intermediate score and $\mathrm{N}$ showing the lowest score. The monensin and urea association promotes weight gain of animals kept on native pastures and supplemented with oat grain.

KEYWORDS: Charolais; ionophore; Nellore, oat. 


\section{INTRODUÇÃO}

No sistema de produção precoce do Sul do Brasil, em que os machos são abatidos e o primeiro acasalamento das fêmeas é realizado aos dois anos de idade, a fase de recria normalmente ocorre em pastagem nativa. Há uma grande variação de qualidade e produtividade da pastagem nativa durante $\mathrm{o}$ ano (RESTLE et al., 2004; CRANCIO et al., 2006; FONTOURA JUNIOR et al., 2007), que reflete no desempenho animal. SOARES et al. (2005) observaram ganhos que variaram de 0,477 a $0,780 \mathrm{~kg} / \mathrm{dia}$ no período primavera/verão, enquanto que no período outono/inverno esses ganhos variaram de $-0,154$ a $0,283 \mathrm{~kg} / \mathrm{dia}$. Sendo assim, a prática da suplementação é uma forma de corrigir esta deficiência nutricional da pastagem nativa de forma completa ou parcial, a fim de permitir maior aporte de nutrientes na dieta total dos animais. De acordo com REZENDE (2010), a suplementação, além de proporcionar aos animais ganhos de peso mais elevados, garante ganhos mais constantes.

Estima-se que, no Rio Grande do Sul, cerca de 1.200.000 ha de aveia sejam implantados anualmente visando à formação de cobertura para os cultivos de verão (soja e milho), o que proporciona em determinados anos excedente de produção de sementes. Com esse excedente, o preço pode ser inferior ao dos alimentos energéticos tradicionais como milho, sorgo, farelo de arroz e farelo de trigo, representando uma opção para a alimentação animal (FATURI et al., 2003; RESTLE et al., 2009). Além disso, FATURI et al. (2003) e RESTLE et al. (2009) observaram que o grão de aveia apresentou 13,08 e $13,68 \%$ de proteína bruta, $29,30 \%$ de FDN e $71,42 \%$ de digestibilidade in vitro da matéria orgânica.

A ação dos ionóforos nos ruminantes ocorre pela alteração que causam no crescimento e no metabolismo dos microorganismos do rúmen, fazendo predominar as bactérias gram negativas em detrimento das gram positivas. Com isso, ocorre aumento na proporção de ácido propiônico e decréscimo dos ácidos acético e butírico (THONNEY et al., 1981), ocorrendo incrementos na eficiência alimentar (DINIUS et al., 1976). ZEOULA et al. (2008) observaram efeito positivo com a adição de monensina na dieta de novilhas recebendo alta fração de concentrado $(50 \%$ com base na matéria seca - MS), registrando aumento da digestibilidade da MS total consumida. Os autores justificam esses resultados pelo incremento da população de bactérias amilolíticas e, consequentemente, maior degradação dos carboidratos não-fibrosos.

Além da queda de produção no período do inverno, a pastagem nativa perde em qualidade, principalmente proteína. Quando a forragem fornecida aos ruminantes é de baixa qualidade nutritiva, normalmente ocorre redução na produção de proteína microbiana no rúmen, resultando em menor produção animal. A uréia é incluída na alimentação de ruminantes com o objetivo de substituir a proteína verdadeira, de maior custo, ou acrescentar nitrogênio em sistemas alimentares com forragens de baixo valor protéico, mantendo, assim, a concentração de amônia ruminal em níveis adequados (OWENS \& BERGEN, 1983).

Objetivou-se com este experimento avaliar a utilização do grão de aveia preta como suplemento energético, associado ou não com monensina sódica e/ou uréia, no desempenho de novilhas de corte de diferentes grupos genéticos na fase de recria, mantidas exclusivamente em campo nativo.

\section{MATERIAL E MÉTODOS}

O experimento foi conduzido no Laboratório de Bovinocultura de Corte do Departamento de Zootecnia da Universidade Federal de Santa Maria - Rio Grande do Sul, situada na região fisiográfica Depressão Central, de janeiro a abril de 2001. O solo pertence à unidade de mapeamento São Pedro, classificado como Argissolo Vermelho amarelo distrófico, que se caracteriza por apresentar solo profundo, avermelhado com textura superficial arenosa, friável e bem drenado (EMBRAPA, 2006).

O desempenho de 116 novilhas de corte contemporâneas classificadas em quatro grupos genéticos - Charolês (C), Nelore $(\mathrm{N})$, mestiças com predominância de $\mathrm{C}(3 / 4 \mathrm{C} 1 / 4 \mathrm{~N}, 5 / 8 \mathrm{C} 3 / 8 \mathrm{~N}$, $11 / 16 \mathrm{C} 5 / 16 \mathrm{~N}$ ) e mestiças com predominância de $\mathrm{N}(3 / 4 \mathrm{~N} 1 / 4 \mathrm{C}, 5 / 8 \mathrm{~N} 3 / 8 \mathrm{C}$ e $11 / 16 \mathrm{~N} 5 / 16 \mathrm{C})$ - foi estudado. As novilhas foram suplementadas com: grão de aveia preta triturado; grão de aveia preta triturado+uréia; grão de aveia preta 
triturado+monensina sódica e grão de aveia preta triturado+uréia+monensina sódica. A quantidade de suplemento foi equivalente a $0,7 \%$ do peso vivo na base seca do início de cada período experimental. As quantidades de uréia foram calculadas para atender a um terço das necessidades de proteína bruta equivalente para ganho de peso diário de $600 \mathrm{~g} / \mathrm{dia}$, de acordo com NRC (1996), sendo corrigida a cada período de acordo com a evolução do peso dos animais.

A suplementação teve a duração de 84 dias, dividida em dois períodos, de 28/01 a 11/03 (final do verão) e de 12/03 a 22/04 (início do outono). Quatorze dias antes de iniciar o experimento, deu-se o início da adaptação dos animais aos suplementos, sendo que, nos que incluíam uréia, iniciou-se a oferta em $30 \mathrm{~g} / \mathrm{animal}$ por dia, aumentando-se $15 \mathrm{~g}$ a cada três dias até atingir a quantidade total calculada de acordo com a sua necessidade de proteína bruta. Nos suplementos que incluíram monensina sódica, iniciou-se com $50 \mathrm{mg}$ de monensina sódica/animal/dia aumentando-se $50 \mathrm{mg}$ a cada três dias, até atingir a quantidade total de 150 $\mathrm{mg} / \mathrm{animal} / \mathrm{dia}$.

Os animais foram mantidos em mesma área de pastagem nativa, totalizando 50 ha, provida de água e sombra natural. Para o fornecimento dos suplementos utilizaram-se quatro piquetes com área individual de $120 \mathrm{~m}^{2}$, providos de cochos de madeira, com acesso de $50 \mathrm{~cm}$ por animal.

Todos os dias pela manhã, às 7:30 h, os animais eram conduzidos ao centro de manejo, localizado próximo aos piquetes de suplementação, e separados de acordo com seus respectivos tratamentos; em seguida, eram conduzidos aos piquetes de suplementação onde recebiam o suplemento. Os animais permaneciam nos piquetes até o consumo total dos respectivos suplementos e, por fim, eram conduzidos novamente ao campo nativo, onde permaneciam até o fornecimento do próximo dia.

O grão de aveia fornecido foi triturado com peneira com malha de três milímetros. Para correção dos macrominerais $\mathrm{Ca}, \mathrm{P}$ e $\mathrm{Na}$, foram utilizadas tabelas de composição nutricional dos alimentos do NRC (1996) para os teores minerais da aveia preta. Como corretivos foram utilizados cloreto de sódio e fosfato bicálcico.

Os animais foram pesados no início da adaptação, no início do período experimental, aos
42 dias e aos 84 dias (final do experimento). Antes de cada pesagem, os animais permaneciam em jejum de sólidos por 12 horas. No momento da pesagem também foi avaliada a condição corporal individual, sendo: 1 - muito magra; 2 - magra; 3 média; 4 - gorda e 5 - muito gorda (RESTLE, 1972).

O método de pastejo foi o contínuo com lotação variável. A estimativa da taxa de acúmulo diário de MS da pastagem nativa foi avaliada em cada período, com o uso de cinco gaiolas de exclusão ao pastejo, adotando-se o método do triplo emparelhamento, no qual cada amostra continha uma área de $0,25 \mathrm{~m}^{2}$. A taxa de acúmulo de matéria seca do período foi estimada por meio da diferença entre o observado dentro da gaiola e o cortado fora da gaiola, dividindo o resultado pela diferença de dias entre os cortes. A disponibilidade de massa de forragem foi avaliada em cada período, tomando-se doze amostras $(0,25$ $\mathrm{m}^{2}$ /amostra) (WILM et al., 1944).

Foram realizadas duas simulações de pastejo, uma em cada período experimental. Logo após coletadas, as amostras foram pesadas, identificadas e acondicionadas em sacos de papel e pré-secadas em estufa com ar forçado a $65^{\circ} \mathrm{C}$ por 72 horas para determinação do teor de matéria seca parcial, sendo sequencialmente trituradas em moinho tipo "Willey" com peneira com malha de um milímetro. Determinou-se o nitrogênio total pelo método micro Kjeldahl, para obtenção do teor de proteína bruta (PB), conforme AOAC (1984), e a digestibilidade "in vitro" da matéria seca (DIVMS) e da matéria orgânica (DIVMO) pela técnica de TILLEY \& TERRY (1963). Os teores de fibra em detergente neutro (FDN) foram determinados pelo método descrito por VAN SOEST \& WINE (1967).

Observou-se (Tabela 1) que houve um aumento de $66,7 \mathrm{~mm}$ na precipitação média mensal ocorrida em relação à normal, demonstrando ter sido um período atípico, ocasionando um decréscimo na insolação ocorrida de 30,4 horas. Já os valores médios para temperaturas máximas mantiveram-se semelhantes; entretanto, nota-se que na transição verão/outono, houve queda acentuada da temperatura média das máximas ocorridas, passando de $30,3^{\circ} \mathrm{C}$ (março) para $25,7^{\circ} \mathrm{C}$ (abril). Em relação às médias das temperaturas mínimas, houve leve aumento de $2,7^{\circ} \mathrm{C}$ da ocorrida em relação à normal. 
Tabela 1 - Precipitação, insolação, temperaturas médias normais e ocorridas no período experimental

\begin{tabular}{|c|c|c|c|c|c|c|c|c|}
\hline \multirow[t]{2}{*}{ Mês } & \multicolumn{2}{|c|}{$\begin{array}{l}\text { Precipitação } \\
\text { (mm) }\end{array}$} & \multicolumn{2}{|c|}{$\begin{array}{l}\text { Insolação } \\
\text { (h) }\end{array}$} & \multicolumn{2}{|c|}{$\begin{array}{l}\text { Temperaturas máximas } \\
\qquad\left({ }^{\circ} \mathrm{C}\right)\end{array}$} & \multicolumn{2}{|c|}{$\begin{array}{c}\text { Temperaturas mínimas } \\
\qquad\left({ }^{\circ} \mathrm{C}\right)\end{array}$} \\
\hline & Normal & Ocorrida & Normal & Ocorrida & Normal & Ocorrida & Normal & Ocorrida \\
\hline Janeiro & 145,1 & 309,9 & 225,2 & 164,6 & 30,4 & 30,0 & 19,1 & 22,0 \\
\hline Fevereiro & 130,2 & 124,8 & 196,7 & 171,6 & 30,0 & 31,3 & 19,5 & 22,0 \\
\hline Março & 151,7 & 144,1 & 197,5 & 191,3 & 28,2 & 30,3 & 17,9 & 20,7 \\
\hline Abril & 134,7 & 249,6 & 168,7 & 138,9 & 25,0 & 25,7 & 14,5 & 17,1 \\
\hline Média & 140,4 & 207,1 & 197,0 & 166,6 & 28,4 & 29,3 & 17,8 & 20,5 \\
\hline
\end{tabular}

Fonte: Estação Meteorológica - UFSM.

O delineamento experimental utilizado foi o inteiramente casualizado, sendo os dados submetidos à análise de variância, teste $\mathrm{F}$, e as médias comparadas pelo teste Tukey, a 5\% de significância.

Os dados foram analisados segundo $\mathrm{o}$ seguinte modelo matemático:

$\mathrm{Y}_{\mathrm{ijklm}}=\mu+\mathrm{T}_{\mathrm{i}}+\mathrm{GG}_{\mathrm{j}}+\mathrm{R}\left(\mathrm{T}^{*} \mathrm{GG}\right)_{\mathrm{ij}}+\mathrm{P}_{\mathrm{k}}+$ $\left(\mathrm{T}^{*} \mathrm{P}\right)_{\mathrm{ik}}+\left(\mathrm{GG}^{*} \mathrm{P}\right)_{\mathrm{jk}}+\mathrm{I}_{1}+\mathrm{E}_{\mathrm{ijklm}}$, em que:

$\mathrm{Y}_{\mathrm{ijklm}}=$ variáveis dependentes; $\mu=$ Média geral de todas as observações; $\mathrm{T}_{\mathrm{i}}=$ efeito do tipo de suplemento de ordem "i", sendo 1=aveia, $2=$ aveia+uréia, $\quad 3=$ aveia+monensina, $\quad 4=$ aveia+monensina+uréia; $\mathrm{GG}_{\mathrm{j}}=$ efeito do grupo genético de ordem " $\mathrm{j}$ ", sendo $1=$ Charolês, $2=$ Nelore, $3=$ mestiças Charolês e $4=$ mestiças Nelore; $\mathrm{R}\left(\mathrm{T}^{*} \mathrm{GG}\right)_{\mathrm{ij}}=$ efeito aleatório baseado na repetição dentro da combinação $\left(\mathrm{T}^{*} \mathrm{GG}\right)_{\mathrm{ij}}\left(\right.$ Erro a); $\mathrm{P}_{\mathrm{k}}=$ efeito do período de suplementação de ordem " $\mathrm{k}$ ", sendo $1=$ final de verão e $2=$ =início do outono; $\left(\mathrm{T}^{*} \mathrm{P}\right)_{\mathrm{ik}}=$ efeito da interação entre o i-ésimo tipo de suplemento com o k-ésimo período de suplementação; $\left(\mathrm{GG}^{*} \mathrm{P}\right)_{\mathrm{jk}}=$ efeito da interação entre o j-ésimo grupo genético com o k-ésimo período de suplementação; $I_{1}=$ efeito da idade inicial dos animais como covariável e $\mathrm{E}_{\mathrm{ijklm}}=$ efeito aleatório residual (Erro b).

Peso inicial e estado corporal inicial foram analisados incluindo no modelo estatístico os efeitos de grupo genético e de idade. Para a realização da análise estatística, utilizou-se o programa estatístico SAS (2000).

\section{RESULTADOS E DISCUSSÃO}

A pastagem nativa apresentou massa de forragem média de 2.370,81 kg MS ha ${ }^{-1}$ (Tabela 2). Com relação à qualidade da pastagem, foram verificados $6,39 \%$ de $\mathrm{PB}, 47,15 \%$ de DIVMS, $43,62 \%$ de DIVMO e 77,41\% de FDN. Analisandose os resultados por período, nota-se que houve queda nos teores de proteína bruta, DIVMS e DIVMO, que, associados ao aumento no teor de FDN, resultaram em redução do ganho de peso, conforme pode ser verificado na Tabela 5. O acúmulo diário de matéria seca apresentou média de 11,61 kg.ha ${ }^{-1} \cdot \mathrm{dia}^{-1}$, sendo que houve declínio com o avanço do período experimental, devido à estacionalidade da produção das espécies que constituem a forragem nativa, composta principalmente por espécies de crescimento estival (SOARES et al., 2005).

Como a massa de forragem média foi elevada, permitindo a seleção do material pastejado, a qualidade da forragem consumida pelos animais, avaliada por meio da simulação de pastejo, apresentou maiores valores de PB e DIVMO, porém, houve similaridade para o teor de FDN.

Houve predominância de gramíneas $(82,47 \%)$ entre as espécies observadas durante a avaliação da composição botânica (Tabela 3). Para os teores de DIVMS e DIVMO, observaram-se valores de 47,15 e 43,62\%, respectivamente. Já para o teor de FDN, que representa a quantidade de parede celular da planta, verificou-se teor elevado $(77,41 \%)$. 
Tabela 2 - Produção e qualidade bromatológica da pastagem nativa total e da pastagem colhida em simulação de pastejo de acordo com o período

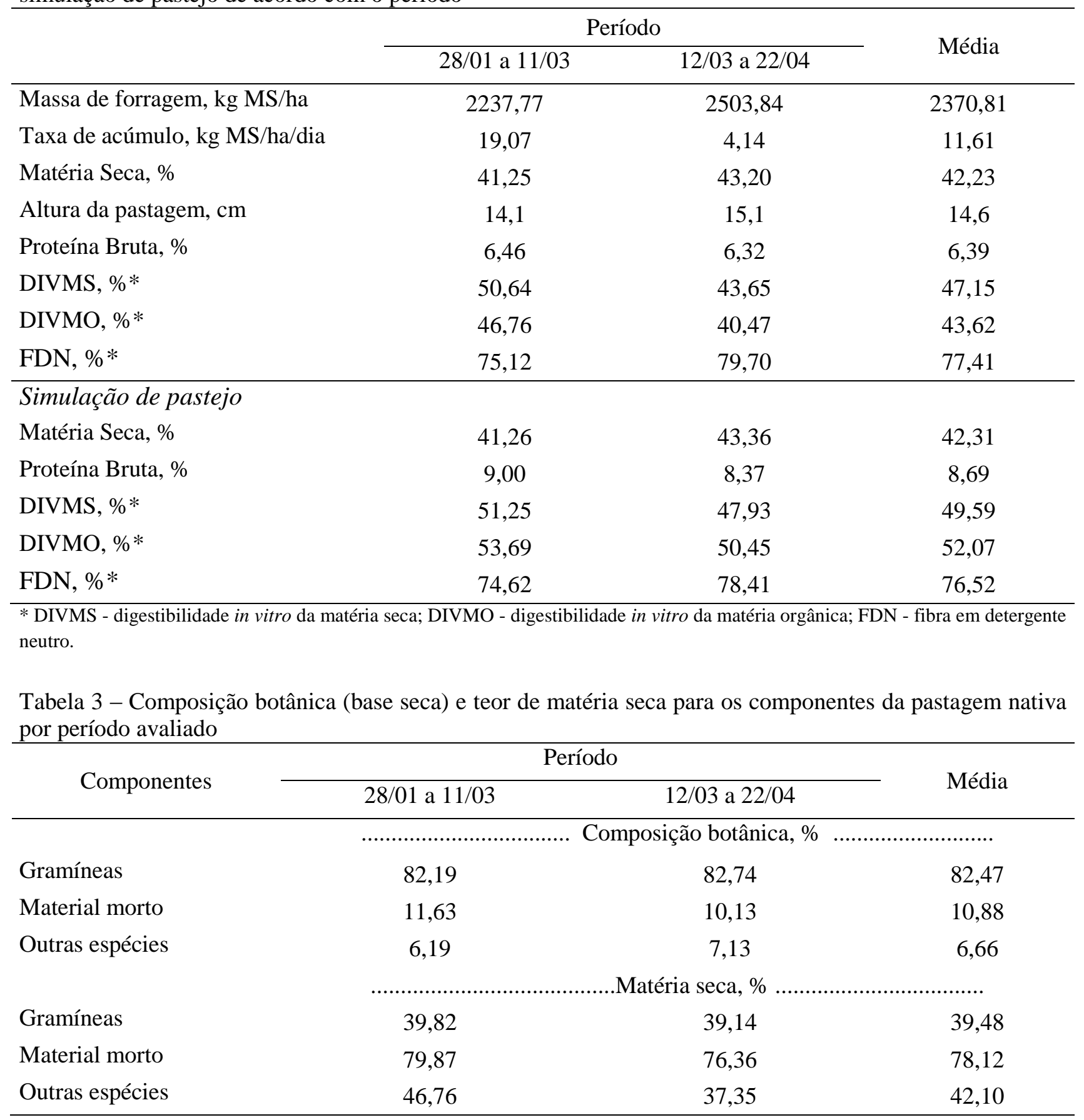

Não houve interação entre o período e os tratamentos alimentares para o ganho de peso médio diário (Tabela 4). Isso já era esperado pela baixa diferença nos parâmetros produtivos e bromatológicos nos dois períodos avaliados (Tabelas 2 e 3). Os animais dos tratamentos aveia+uréia+monensina e aveia+monensina apresentaram maior $(\mathrm{P}<0,05)$ ganho de peso médio diário (GMD) em relação aos animais que receberam aveia+uréia como suplemento. Nota-se que a inclusão de monensina na dieta favoreceu o GMD dos animais.

Em pesquisa realizada por GOODRICH et al. (1984), verificou-se que animais mantidos em pastagem e suplementados com monensina sódica ganharam $13,5 \%$ mais peso que animais controle. ROSO \& RESTLE (2000), trabalhando em pastagem cultivada de inverno, verificaram aumento de $7 \%$ na carga animal média, $6,9 \%$ no ganho de peso vivo/ha e $6 \%$ na eficiência alimentar de novilhas de corte 
suplementadas com lasalocida sódica via cloreto de sódio, em relação aos animais suplementados apenas com cloreto de sódio. RESTLE et al. (1999) não encontraram efeito da inclusão de lasalocida sódica no suplemento de novilhos terminados em pastagem de aveia preta e azevém. osmari et al. (2008) não observaram efeito da monensina sódica no desempenho de vacas de descarte terminadas em campo nativo recebendo suplementação.

Tabela 4 - Médias ajustadas e erros-padrão para ganho de peso médio diário (g) de acordo com o tratamento e o período

\begin{tabular}{lccc}
\hline \multirow{2}{*}{ Tratamento } & \multicolumn{2}{c}{ Período } & \multirow{2}{*}{ Média } \\
\cline { 2 - 3 } & $28 / 01$ a $11 / 03$ & $12 / 03$ a $22 / 04$ & \\
\hline Aveia & $471 \pm 36$ & $390 \pm 39$ & $430^{\mathrm{BC}} \pm 28$ \\
Aveia+uréia & $458 \pm 35$ & $302 \pm 35$ & $380^{\mathrm{C}} \pm 26$ \\
Aveia+monensina & $563 \pm 62$ & $413 \pm 62$ & $488^{\mathrm{AB}} \pm 57$ \\
Aveia+ monensina+uréia & $608 \pm 45$ & $471 \pm 45$ & $539^{\mathrm{A}} \pm 38$ \\
Média & $525^{\mathrm{a}} \pm 19$ & $394^{\mathrm{b}} \pm 19$ &
\end{tabular}

${ }^{a, b}$ Médias seguidas de letras minúsculas diferentes, na linha, diferem $(\mathrm{P}<0,05)$ pelo teste $\mathrm{F}$.

${ }^{\text {A,B,C }}$ Médias seguidas de letras maiúsculas diferentes, na coluna, diferem $(\mathrm{P}<0,05)$ pelo teste Tukey.

Trabalhos de pesquisa explicam o benefício da adição de ionóforos na dieta de bovinos de corte por meio do incremento na proporção de ácido propiônico e decréscimo na de ácidos acético e butírico (GOODRICH et al., 1984), ocorrendo incremento na eficiência alimentar devido ao ácido propiônico ser energeticamente mais eficiente (DINIUS et al., 1976). Sendo o ácido propiônico eficiente precursor da glicose, obtém-se maior utilização de aminoácidos para síntese de proteína, devido à diminuição da utilização deste para gliconeogênese (SALLES et al., 2001).

Verifica-se, ainda, que o ganho de peso médio diário para o tratamento aveia+uréia $(380 \mathrm{~g})$ foi similar ao tratamento aveia (430 g) e inferior aos demais tratamentos avaliados (Tabela 4). Isso pode ser explicado pelos parâmetros ruminais, em que provavelmente a inclusão de uréia ao suplemento fez com que os níveis de $\mathrm{N}-\mathrm{NH}_{3}$ se elevassem a ponto de limitar o desenvolvimento da microbiota ruminal. De acordo com SATTER \& SLYTER (1974), concentrações de $\mathrm{N}^{-\mathrm{NH}_{3}}$ em torno de $5 \mathrm{mg} / 100 \mathrm{~mL}$ de fluido são sugeridas como adequadas para maximizar o desenvolvimento microbiano ruminal, sendo que concentrações superiores representam um excesso que não é aproveitado para a síntese microbiana. Portanto, isso causa produção e absorção excessiva de amônia que aumentam a excreção de $\mathrm{N}$ e o custo energético de produção de uréia (RUSSEL et al., 1992).

Ao verificar o ganho de peso dos animais alimentados com uréia+monensina, houve efeito associativo benéfico. Isso pode ser explicado pelo efeito da monensina na redução da produção de amônia, como verificado por OLIVEIRA et al. (2007) e LANA \& FOX (2001). Resultados similares foram relatados por Salles et al. (2001), que observaram grande quantidade de amônia acumulada no rúmen de animais submetidos a dietas com excesso de uréia. Nessa situação, a adição de monensina faz diminuir a amônia em $30 \%$ e os aminoácidos poupados da desaminação são utilizados por outras bactérias, aumentando a concentração de proteína bacteriana no fluido ruminal. Isso provavelmente ocorreu tendo em vista que o tratamento aveia+uréia+monensina foi similar $(\mathrm{P}>0,05)$ ao aveia+monensina e ambos superiores ao aveia+uréia.

A presença de uréia na dieta com monensina não favoreceu o desempenho animal em comparação àquela apenas com monensina. GELINSKI et al. (2000) e RODRIGUES et al. (2007) também não encontraram interação entre monensina $\mathrm{x}$ uréia. LANA et al. (1997) explica que a monensina tende a melhorar a eficiência de utilização do nitrogênio em dietas à base de proteína verdadeira (farelo de soja), em vez de nitrogênio não-protéico (uréia), condição diferente da utilizada neste experimento, em que a dieta proporcionava menores níveis de PB (Tabela 2) ou era suplementada com fonte de nitrogênio nãoprotéico.

BARBOSA et al. (2001), avaliando a fermentação de três fontes de proteína e três fontes de energia associadas a dois tipos de ionóforo, 
encontraram resultados que condizem, com os valores de desempenho verificados no presente experimento. Segundo esses autores, na análise dos parâmetros ruminais, a concentração de proteína microbiana no meio de cultura decresceu com o uso de uréia e farelo de soja e cresceu com o de glúten de milho, provavelmente devido à maior disponibilidade energética do glúten e à falta de peptídeos no caso da uréia. Também verificaram que as concentrações de amônia e proteína microbiana estavam altamente correlacionadas com o $\mathrm{pH}$ final, percentagem de proteína bruta e tipo de alimento, havendo menor correlação com a presença do ionóforo. No caso da amônia e conforme relatado para a proteína solúvel, esses efeitos foram atribuídos à presença da uréia, que elevou $\mathrm{o} \mathrm{pH}$ do meio, e à maior quantidade de nitrogênio incubado. Concluíram que a monensina teve maior efeito na redução da produção de amônia de fontes de proteína de maior degradabilidade $(71,4$ para a uréia contra 24,8 mM para o farelo de soja).

Associando monensina a uma fonte de proteína verdadeira ou NNP na dieta de bovinos de corte confinados, LANA \& FOX (2001) não encontraram alterações na eficiência de dietas contendo uréia. Já HANSON \& KLOPFENSTEIN (1979), suplementando novilhos com monensina adicionada à proteína natural ou uréia, observaram melhor desempenho para os animais suplementados com proteína natural, indicando que o fator limitante para o ganho de peso e eficiência alimentar para o suplemento com uréia foi em função da menor quantidade de proteína que chegou ao intestino.

Observando as médias em relação aos períodos, nota-se que houve decréscimo $(\mathrm{P}<0,05)$ no ganho de peso médio diário de $525 \pm 19$ para $394 \pm$ $19 \mathrm{~g}$, do primeiro para o segundo período, devido à queda qualitativa da forragem consumida (Tabelas 2 , 3 e 4), o que está de acordo com os dados de SOARES et al. (2005). Esses autores, trabalhando com diferentes ofertas de forragem em campo nativo, observaram queda no GMD dos novilhos de, aproximadamente, 400 gramas em todos os tratamentos, do verão para o outono. No presente estudo, a queda no GMD não foi tão acentuada, demonstrando o benefício da suplementação energética em épocas estratégicas.

Houve interação significativa entre grupo genético e período (Tabela 5). Analisando o primeiro período (28/01 a 11/03) que corresponde ao final do verão, observa-se diferença significativa a favor das mestiças Nelore em relação aos Charolês (691 contra 370 g). Já no segundo período, essa diferença deixou de existir. O maior ganho de peso das mestiças Nelore no primeiro período deve-se à incorporação de genes da raça Charolês, que expressam maior potencial para ganho de peso (MENEZES \& RESTLE, 2005), associados ao da raça Nelore, que apresentam maior adaptabilidade ao clima quente (PEREIRA et al., 2000). Além disso, a heterozigose também afeta positivamente o ganho de peso (MENEZES \& RESTLE, 2005).

Tabela 5 - Médias ajustadas e erros-padrão para ganho de peso médio diário (g) de acordo com o grupo genético e o período

\begin{tabular}{lcccc}
\hline \multirow{2}{*}{ Grupo genético } & $\mathrm{n}$ & \multicolumn{2}{c}{ Período } & \multirow{2}{*}{ Média } \\
\cline { 3 - 4 } & & $28 / 01 \mathrm{a} \mathrm{11/03}$ & $12 / 03 \mathrm{a} 22 / 04$ & \\
\hline Charolês & 23 & $370^{\mathrm{bc}} \pm 52$ & $427^{\mathrm{bc}} \pm 55$ & $411 \pm 34$ \\
Mestiças Charolês & 37 & $517^{\mathrm{abc}} \pm 43$ & $398^{\mathrm{bc}} \pm 43$ & $471 \pm 26$ \\
Nelore & 13 & $560^{\mathrm{ab}} \pm 73$ & $317^{\mathrm{c}} \pm 73$ & $390 \pm 64$ \\
Mestiças Nelore & 43 & $691^{\mathrm{a}} \pm 40$ & $397^{\mathrm{bc}} \pm 40$ & $566 \pm 28$ \\
Média & & $525 \pm 19$ & $394 \pm 19$ & \\
\hline
\end{tabular}

a,b,c Médias seguidas de letras diferentes, diferem $(\mathrm{P}<0,05)$ pelo teste Tukey.

PEREIRA et al. (2000) verificaram, em animais na fase de crescimento em condições de pastagem, maior ganho de peso dos Charolês do que dos Nelore durante o inverno e maior ganho de peso dos Nelore durante o verão. Verificou-se que o ganho de peso médio diário das novilhas Charolês e mestiças Charolês não sofreu alteração significativa $(\mathrm{P}>0,05)$ do final do verão para o início do outono. Já nas novilhas Nelore e mestiças Nelore, a queda foi significativa $(\mathrm{P}<0,05)$, provavelmente influenciada 
pela queda na temperatura (Tabela 1 ).

$\mathrm{Na}$ Tabela 6, verifica-se que os animais

Nelore apresentaram sempre os menores pesos tanto ao início quanto ao final de cada período em relação aos demais grupos genéticos.

Tabela 6 - Médias ajustadas e erros-padrão para peso vivo de acordo com o grupo genético e período

\begin{tabular}{lccc}
\hline \multirow{2}{*}{ Grupo genético } & \multicolumn{3}{c}{ Peso vivo (kg) } \\
\cline { 2 - 4 } & Inicial $(28 / 01)$ & Final $1^{\circ}$ Período (11/03) & Final $2^{\circ}$ Período (22/04) \\
\hline Charolês & $262,5^{\mathrm{ab}} \pm 6,7$ & $277,1^{\mathrm{a}} \pm 7,5$ & $292,2^{\mathrm{a}} \pm 7,8$ \\
Mestiças Charolês & $276,9^{\mathrm{a}} \pm 5,5$ & $298,6^{\mathrm{a}} \pm 6,1$ & $318,3^{\mathrm{a}} \pm 6,1$ \\
Nelore & $188,6^{\mathrm{c}} \pm 9,0$ & $213,3^{\mathrm{b}} \pm 10,1$ & $226,7^{\mathrm{b}} \pm 10,1$ \\
Mestiças Nelore & $244,4^{\mathrm{b}} \pm 5,2$ & $273,2^{\mathrm{a}} \pm 6,1$ & $290,2^{\mathrm{a}} \pm 5,8$ \\
\cline { 2 - 4 } & & Escore corporal (pontos) \\
\hline Charolês & $3,02^{\mathrm{a}} \pm 0,04$ & $3,10^{\mathrm{b}} \pm 0,04$ \\
Mestiças Charolês & $3,16^{\mathrm{a}} \pm 0,03$ & $3,31^{\mathrm{a}} \pm 0,03$ & $3,20^{\mathrm{b}} \pm 0,04$ \\
Nelore & $2,83^{\mathrm{b}} \pm 0,05$ & $2,97^{\mathrm{c}} \pm 0,05$ & $3,38^{\mathrm{a}} \pm 0,03$ \\
Mestiças Nelore & $3,06^{\mathrm{a}} \pm 0,03$ & $3,23^{\mathrm{ab}} \pm 0,03$ & $3,04^{\mathrm{c}} \pm 0,05$ \\
& & & $3,31^{\mathrm{ab}} \pm 0,03$ \\
\hline
\end{tabular}

a,b,c Médias seguidas de letras diferentes, na coluna, diferem $(\mathrm{P}<0,05)$ pelo teste Tukey.

A maior velocidade de crescimento das novilhas Charolês faz com que essa raça atinja o peso adulto mais rapidamente. Terminando novilhos em confinamento, MENEZES \& RESTLE (2005) constataram maior efeito genético aditivo para peso dos Charolês, sendo os mesmos sempre mais pesados que os Nelore. O maior potencial genético para ganho de peso indica que o Charolês apresenta maior efeito aditivo de gene para a característica ganho de peso que o Nelore. Isso fica evidente também quando o peso das mestiças é comparado ao das Nelore.

O grupo genético Nelore apresentou valores inferiores de escore corporal em todos os períodos avaliados em relação aos demais grupos genéticos. Sabendo-se que a condição corporal reflete as reservas energéticas, a utilização de escalas numéricas para classificar as fêmeas segundo sua condição corporal tem demonstrado ser uma importante ferramenta para melhorar o manejo nutricional das mesmas.

Em animais destinados ao abate, a condição corporal é uma maneira de se estimar o grau de acabamento dos animais. Em fêmeas bovinas destinadas à reprodução, a quantidade de gordura corporal em estágios específicos do seu ciclo produtivo é importante para determinação do seu desempenho reprodutivo. Decisões sobre o manejo nutricional são feitas com mais precisão quando a avaliação da condição corporal é rotineiramente utilizada. Variações qualitativas ocorridas na pastagem ofertada são causa comum de baixas condições corporais e, consequentemente, falhas reprodutivas. Esses comentários ficam bem evidentes ao se analisar os resultados de VAZ \& RESTLE (2000), que submeteram novilhas a três níveis de suplementação $(0,0,35$ e $0,70 \%$ do peso vivo), mantidas em campo nativo, e verificaram que o ganho de peso e a condição corporal no final do período de suplementação aumentou de maneira linear, acompanhando o nível de suplementação.

Na Tabela 7, apesar de não ser possível a análise estatística, observa-se que os tratamentos que incluíram monensina apresentaram maior eficiência em transformar o suplemento em ganho de peso. Essa afirmação vem ao encontro do observado por ZEOULA et al. (2008), com dietas com relação volumoso/concentrado de 50:50, nas quais a adição de monensina sódica à dieta apresentou efeito benéfico sobre a fermentação ruminal e a utilização de nutrientes em bovinos e bubalinos. PRADO et al. (2010), ao alimentar búfalos com $80 \%$ de volumoso na dieta, concluíram que a monensina sódica aumenta a digestibilidade total e intestinal dos componentes nutritivos. 
Tabela 7 - Consumo médio diário e total de suplemento, ganho de peso médio diário, eficiência da suplementação e diferença relativa de acordo com o tratamento

\begin{tabular}{lcccc}
\hline & \multicolumn{3}{c}{ Tratamento } \\
\cline { 2 - 5 } & Aveia & $\begin{array}{c}\text { Aveia+ } \\
\text { uréia }\end{array}$ & $\begin{array}{c}\text { Aveia+ } \\
\text { monensina }\end{array}$ & $\begin{array}{c}\text { Aveia+ } \\
\text { monensina+ } \\
\text { uréia }\end{array}$ \\
\hline Consumo diário, kg/animal/dia & 1,84 & 1,86 & 1,90 & 1,90 \\
Consumo total (A), kg/animal & 154,81 & 155,98 & 159,44 & 159,66 \\
Ganho de peso (B), kg & 35,59 & 33,83 & 44,55 & 46,10 \\
Conversão (A/B) & 4,35 & 4,61 & 3,58 & 3,46 \\
Diferença relativa, \%* & 100,0 & 105,9 & 82,3 & 79,5 \\
\hline
\end{tabular}

* Em relação à Eficiência.

** Dados não analisados estatisticamente

\section{CONCLUSÕES}

A associação da monensina com uréia favorece o ganho de peso dos animais mantidos em campo nativo e suplementados com grão de aveia.

Genótipos com predominância Nelore apresentam maior ganho de peso e em condição corporal do que as Charolês no final do verão. No entanto, as primeiras sofreram queda acentuada no seu desempenho no início do outono.

\section{AGRADECIMENTOS}

Ao Prof. PhD José Henrique Souza da Silva pelo auxílio nas análises estatísticas. A todos os alunos bolsistas e estagiários do Laboratório de Bovinocultura de Corte da UFSM, que de alguma forma contribuíram para a realização deste experimento.

\section{REFERÊNCIAS}

A.O.A.C. ASSOCIATION OF OFFICIAL AGRICULTURAL CHEMISTS. Official Methods Analysis, Washington: William, S. 1984. 1141p.

BARBOSA, N.G.S.; LANA, R.P.; MÂNCIO, A.B. BORGES, A. C.; QUEIROZ, C. de; OLIVEIRA, J. S. Fermentação da proteína de seis alimentos por microorganismos ruminais, incubados puros ou com monensina ou rumensin. Revista Brasileira de Zootecnia, v.30, n.4, p.1316-1324, 2001.

CRANCIO, L.A.; CARVALHO, P.C.F.; NABINGER, C. SILVA, J. L. S. da; SANTOS, R. J. dos; SANTOS, D. T. dos; PELLEGRINI, L. G. de. Ganho de peso de novilhas em pastagem nativa da Serra do Sudeste do RS submetida ao controle de plantas indesejáveis e intensidades de pastejo. Ciência Rural, v.36, n.4, p.1265-1271, 2006.

DINIUS, D.A.; BRANDT, R.T.; HARMON, D.L. Effect of monensin fed with forage on digestion and the ruminal ecosystem of steers. Journal of Animal Science, v.42, n.1, p.229-234, 1976.

EMBRAPA - CNPS. Sistema brasileiro de classificação de solos. $2^{a}$. Edição. Brasília: EMBRAPA. Rio de Janeiro, 2006. 412p.

FATURI, C.; RESTLE, J.; BRONDANI, I.L. ALVES FILHO, D. C.; ROSA, J. R. P.; KUSS, F.; MENEZES, L. F. G. de. Grão de aveia preta em substituição ao grão de sorgo para alimentação de novilhos na fase de terminação. Revista Brasileira de Zootecnia, v.32, n.2, p.437-448, 2003.

FONTOURA JÚNIOR, J.A.S.; CARVALHO, P.C.F.; NABINGER, C. SILVA, J. L. S. da; PINTO, C. E.; CRANCIO, L. A.. Produção Animal em pastagem nativa submetida ao controle de plantas indesejáveis e a intensidade de pastejo. Ciência Rural, v.37, n.1, p.247252, 2007.

GELINSKI, L.A.M.; ANDRIGUETTO, J.L.; ROSSI JR., P. Monensina e uréia de liberação lenta no desempenho de bovinos confinados. Archives of Veterinary Science, v.5, n.1, p.137-140, 2000

GOODRICH, R.D.; GARRET, J.E.; GAST, D.R. KIRICK, M. A.; LARSON, D. A.; MEISKE, J. C.Influence of monensin on the performance of cattle. Journal of Animal Science, v.58, n. 6 p.1484-1498, 1984.

HANSON, T.L.; KLOPFENSTEIN, T. Monensin, protein source and protein levels of growing steers. Journal of Animal Science, v.48, p.474-479, 1979.

KNORR, M.; PATINO, H.O.; SILVEIRA, A.L.F. MÜHLBACH, P.R. F.; MALLMANN, G. M.; MEDEIROS, F. S.Desempenho de novilhos suplementados com sais proteinados em pastagem nativa. Pesquisa Agropecuária Brasileira, Brasília, v.40, n.8, p.783-788, ago. 2005

KUSS, F.; RESTLE, J.; PASCOAL, L.L. SANTOS, A. P. dos; MENEZES, L. F. G. de; OSMARI, M. P. Desempenho de vacas de descarte recebendo dietas com ou sem monensina. Ciência Rural, v.38, n.1, p.173-177, 2008. 
LANA, R.P.; FOX, D.G.; RUSSELL, J.B. ; PERRY, T. C. Influence of monensin on Holstein steers fed highconcentrate diets containing soybean meal or urea. Journal of Animal Science, v. 75, n.10, p.2571-2579, 1997.

LANA, R.P.: FOX, D.G. Interações entre monensina sódica, óleo de soja e fontes de nitrogênio no desempenho de novilhos Aberdeen Angus em confinamento. Revista Brasileira de Zootecnia, v.30, n.1, p.247-253, 2001.

MENEZES, L.F.G.; RESTLE, J. Desempenho de novilhos de gerações avançadas do cruzamento alternado entre as raças Charolês e Nelore, terminadas em confinamento. Revista Brasileira de Zootecnia, v.34, n.6, p.1927-1937, 2005.

NATIONAL RESEARCH COUNCIL - NRC. Nutrient requeriment of beef cattle. $7^{\circ}$ Ed., Washington, DC, 1996, 232p.

OLIVEIRA, M.V.M; LANA, R.P.; EIFERT, E.C. LUZ, D. F.; PEREIRA, J. C.; PÉREZ, J. R. O.; VARGAS JUNIOR, F. M. de. Influência da monensina sódicano consumo e na digestibilidade de dietas com diferentes teores de proteína para ovinos. Revista Brasileira de Zootecnia, v.36, n.3, p.643-651, 2007.

OLIVEIRA, M.V.M.; LANA, R.P.; EIFERT, E.C. LUZ, D. F.; VARGAS JUNIOR, F. M. de. Desempenho de novilhas Holandesas confinadas com dietas com diferentes níveis de monensina sódica. Revista Brasileira de Zootecnia, v.38, n.9, p.1835-1840, 2009.

OSMARI, M.P.; ARBOITTE, M.Z.; BRONDANI, I.L. KUSS, F.; ALVES FILHO, D. C.; RESTLE J. Vacas terminadas em campo nativo suplementadas com farelo de trigo ou farelo de arroz integral contendo ou não monensina sódica. Ciência e Agrotecnologia, v.32, n.6, p.1974-1980, 2008.

OWENS, F.N.; BERGEN, W.G. Nitrogen metabolismo f ruminant animals: Historical perpective, current understanding, and future implications. Journal of Animal Science, v.57, p. 498-504, 1983.

PEREIRA, L.P; RESTLE, J.; SILVA, J.H.S. Desenvolvimento ponderal de bovinos de corte de diferentes grupos genéticos de Charolês x Nelore inteiros ou castrados aos oito meses. Ciência Rural, v.30, n.3, p.409-412, 2000

PARDO, R.M.P. ; FISCHER, V. ; BALBINOTTI, M. MORENO, C. B.; FERREIRA, E. X.; VINHAS, R. I.; MONKS, P. L. Níveis crescentes de suplementação energética sobre o desenvolvimento de novilhos mantidos em pastagem natural na encosta sudeste do Rio Grande do sul. Revista Brasileira de Zootecnia, v.32, n.6, p.13971407, 2003.

PRADO, O.P.P.; ZEOULA, L.M.; MOURA, L.P.P. FRANCO, S. L.; PRADO, I. N. do; JACOBI, G. Efeito da adição de própolis e monensina sódica na digestibilidade e características ruminais em bubalinos alimentados com dietas a base de forragem. Revista Brasileira de Zootecnia, v.39, n.9, p.2055-2065, 2010.
RESTLE, J. Comportamento reprodutivo do rebanho de gado de corte da Fazenda Experimental de Criação da Estação Experimental Agronômica da UFRGS. Curso de Pós-Graduação em Agronomia, UFRGS, 1972.

RESTLE, J.; SOARES, A.B.; FERREIRA, M.V. BRONDANI, I. L.; CALÇA, K. G.Suplementação associada com lasalocida para novilhos em terminação em pastagem cultivada de inverno. Ciência Rural, v.29, n.3, p.555-559, 1999.

RESTLE, J.; NEUMANN, M.; ALVES FILHO, D.C. PASCOAL, L. L.; ROSA, J. R. P.; MENEZES, L. F. G. de; PELLEGRINI, L. G. de. Terminação em confinamento de vacas e novilhas sob dietas com ou sem monensina sódica. Revista Brasileira de Zootecnia, v.30, n.6, p.1801-1812, 2001

RESTLE, J., PACHECO, P.S.; PÁDUA, J.T. ROCHA, M. G. da; VAZ, R. Z.; EIFERT, E. da C.; MOLETTA, J. L.; FREITAS, A. K. de. Eficiência biológica de vacas de dois grupos genéticos amamentando bezerros puros ou F1, mantidas em diferentes condições de alimentação. Revista Brasileira de Zootecnia, v.33, n.6, sup. 1 p.1822-1832, 2004.

RESTLE, J.; FATURI, C.; PASCOAL, L.L. ROSA, J.R. P.; BRONDANI, I. L.; ALVES FILHO, D. C. Processamento do grão de aveia para alimentação de vacas de descarte terminadas em confinamento. Ciência Animal Brasileira, v.10, n.2, p.496-503, 2009.

REZENDE, P., L., P. Desempenho na fase de recria e características da carcaça de bovinos de origem leiteira submetidos a diferentes estratégias de alimentação. Goiânia: Universidade Federal de Goiás, 2010. 64p. Dissertação (Mestrado em Zootecnia) Universidade Federal Goiás, 2010. Disponível em http://www.vet.ufg.br/ppgca//uploads/files/66/Dissertacao 2010_Pedro_Leonardo.pdf

RODRIGUES, P.H.M.; PEIXOTO JUNIOR, K.C.; MORGULLIS, S.C.F. SILVA, E. J. A. da; MEYER, P. M.; PIRES, A. V. Avaliação da monensina administrada pela forma convencional ou por dispositivo de liberação lenta (bólus) em bovinos alimentados com forragens de baixo valor nutritivo e suplementados ou não com uréia. Revista Brasileira de Zootecnia, v.36, n.6, p.1937-1944, 2007.

ROSO, C.; RESTLE, J. Lasalocida sódica suplementada via sal para fêmeas de corte mantidas em pastagem cultivada de estação fria. Revista Brasileira de Zootecnia, v.30, n.3, p.830-834, 2000.

RUSSEL, J.B.; O'CONNOR, J.D.; FOX, D.G VAN SOEST, P. J.; SNIFFEN C. J. A net carbohydrate and protein system to evaluating cattle diets. I. Ruminal fermentation. Journal of Animal Science, v.70,n. 11, p.3551-3561, 1992.

SALLES, M.S.V.; ZANETTI, M.A.; CONTI, R.M.C., LIMA, C. G. de. Efeitos da monensina no desempenho de bezerras leiteiras em crescimento. Revista Brasileira de Zootecnia, v.30, n.4, p.1293-1298, 2001. 
SAS Institute. SAS/STATÒ. User's guide: statistics, version 8.1. 4.ed., v.2, Cary: SAS Institute, 2000.

SATTER, L.D.; SLYTER, L.L. Effect of ammonia concentration on rumen microbial protein production in vitro. Brithish Journal of Nutrition, v.32, n.199-205, 1974.

SOARES, A.B.; CARVALHO, P.C.F.; NABINGER, C. SEMMELMANN, C.; TRINDADE, J. K. da; GUERRA, E.; FREITAS, T. S. de; PINTO, C. E.; FONTOURA JÚNIOR, J. A.; FRIZZO, A.. Produção Animal e de forragem em pastagem nativa submetida a distintas ofertas de forragem. Ciência Rural, v.35, n.5, p.1148-1154, 2005.

THONNEY, E.; HEIDE, K.; DUHAIME, D.J. Growth, feed efficiency and metabolite concentration of cattle feed high forage diets with lasalocid or monensin supplements. Journal of Animal Science, v.52, p.427433, 1981.

TILLEY, J.M.A.; TERRY, R.A. Atwo-stage technique for the "in vitro" digestion of forrage crop. Journal of British Grassland Society. Hurley, v.18, n.2, p.104-111, 1963.
VAN SOEST, P.J.; WINE, R.H. Use of detergents in analysis of fibrous feeds. IV. Determinations of plant cellwall constituents. Journal of Association Official Analysis Chemists, p.50:50, 1967.

VAZ, R.Z.; RESTLE, J. Níveis de suplementação para novilhas durante o $1^{\circ}$ período reprodutivo dos 14 aos 17 meses. II- Desempenho reprodutivo. In: REUNIÃO ANUAL DA SOCIEDADE BRASILEIRA DE ZOOTECNIA, 37, 2000, Viçosa. Anais... Viçosa: SBZ, 2000.Disponível em http://www.sbz.org.br/reuniaoanual/anais/arq_reuniao_an ual/sbz2000.rar

ZEOULA, L.M.; BELEZE, J.R.F.; GERON, L.J.V. MAEDA, E. M.; PRADO, I. N. do; PAULA, M.C. de. Digestibilidade parcial e total de rações com a inclusão de ionóforos ou probióticos para bubalinos bovinos. Revista Brasileira de Zootecnia, v. 37, n. 3, p.563-571, 2008.

WILM, H.G.; COSTELLO, O.F.; KLIPPLE, G.E.

Estimating forage yield by the double sampling method. Journal American Society Agronomy, v.36, n.1, 194203, 1944 